\title{
Feurs - 10 boulevard de l'Hippodrome
}

$n^{\circ} 2211394$

\section{Éric Thévenin}

\section{(2) OpenEdition}

Édition électronique

URL : http://journals.openedition.org/adlfi/15215

ISSN : 2114-0502

Éditeur

Ministère de la culture

Référence électronique

Éric Thévenin, «Feurs - 10 boulevard de l'Hippodrome », ADLFI. Archéologie de la France - Informations [En ligne], Rhône-Alpes, mis en ligne le 11 août 2015, consulté le 19 avril 2019. URL : http:// journals.openedition.org/adlfi/15215

Ce document a été généré automatiquement le 19 avril 2019

(C) Ministère de la Culture et de la Communication, CNRS 


\title{
Feurs - 10 boulevard de l'Hippodrome
} $n^{\circ} 2211394$

\author{
Éric Thévenin
}

Lien Atlas (MCC) :

http://atlas.patrimoines.culture.fr/atlas/trunk/index.php?

ap_theme=DOM_2.01.02\&ap_bbox=4.188;45.704;4.274;45.760

1 L'intervention du 4 au 5 novembre 2013 se rapporte au projet d'aménagement d'un lotissement de huit maisons individuelles engagé sur cette commune.

2 Situé en bordure de la Loire au sud-ouest de l'agglomération, le diagnostic de $4400 \mathrm{~m}^{2}$ concernait trois parcelles sans relief référencées AO 124, 334 et 523. La stratigraphie du site est homogène sur l'ensemble de la zone, car dépourvue de recouvrement. La stratigraphie générale est simple : une couche de terre végétale, une couche de remblai, puis le terrain naturel caractérisé ici par des alluvions anciennes.

3 Le secteur peu documenté en découvertes pré- ou protohistoriques (indices d'une occupation néolithique à $180 \mathrm{~m}$ au nord du diagnostic) se trouve localisé en rive droite, à 300 mètres de la Loire et de son affluent le Soleillant, entre la ville antique de Feurs au nord-est et le secteur de Randan au sud-ouest, mentionné à de très nombreuses reprises dans les sources historiques.

4 Deux occupations se seraient succédé sur cette petite butte située en bordure du fleuve. La première occupation serait datée de l'Antiquité avec la présence supposée d'une nécropole et d'un grand et hypothétique monument cultuel (hypothèse aujourd'hui abandonnée au profit d'un monument du haut Moyen Âge). Plus vraisemblable, la seconde occupation se serait développée autour d'une église et d'un prieuré dont la première mention remonterait à l'an 945. Relevant de l'Abbaye de Savigny, le prieuré pourrait avoir été fortifié ou confiné dans l'enceinte d'un château (Perronet, 1980). Le démantèlement du mur d'enceinte du prieuré, à la fin du XIve s., serait contemporain de 
la construction du rempart de la ville. D'autres importantes découvertes sont intervenues en 1988 à l'est du diagnostic à l'occasion de travaux dans le périmètre de l'actuel hippodrome. La présence de murs arasés, de bassins et d'aménagements hydrauliques laisse entrevoir les restes architecturaux d'un sanctuaire ou d'une vaste villa à cet endroit (Lavendhomme, 1997).

Le seul vestige découvert durant cette opération est daté de la période médiévale, plus précisément des $\mathrm{XII}^{\mathrm{e}}$ et $\mathrm{XIII}^{\mathrm{e}} \mathrm{s}$. Il s'agit d'un important ouvrage fossoyé de $5,80 \mathrm{~m}$ de large pour une profondeur maximale de $1,40 \mathrm{~m}$, relevé sur une longueur de près de 30 mètres le long de la limite ouest du diagnostic. Cet aménagement très légèrement curviligne, d'orientation nord-ouest/sud-est est présent dans les sondages 6,7 et 8 où il a fait l'objet d'un relevé stratigraphique. Son niveau d'ouverture se situe à $0,80 \mathrm{~m}$ du sol actuel, entre 334,62 et 334,20 m NGF.

6 Le creusement plus large que profond s'ouvre sur des parois irrégulières très largement évasées. Le fond peu marqué présente un profil légèrement concave, large de 2,20 $\mathrm{m}$.

Deux grandes séquences participent au remplissage du fossé. La première séquence de comblement occupe depuis le fond les deux tiers du fossé. Elle se présente sous la forme d'une couche homogène à matrice sablo-limoneuse brun foncé. Riche en particules charbonneuses, elle contient l'intégralité du mobilier médiéval. À sa base s'est constitué un horizon organique gris sombre de quelques centimètres d'épaisseur. La seconde séquence montre une évolution plus hétérogène du processus. Comblant le dernier tiers supérieur du fossé, celle-ci rassemble deux couches stériles, l'une constituée majoritairement de galets, l'autre de sables indurés brun-clair de plus faible impact. L'accumulation des galets semble avoir été progressive durant toute la période de fonctionnement du fossé d'où la présence limitée d'inclusions caillouteuses dans la partie inférieure du creusement. Ce n'est qu'en phase d'abandon que l'apport devient massif, accélérant le nivellement puis le scellement du fossé. La présence d'un talus (constitué de matériaux d'extraction) en bordure ouest de l'ouvrage peut expliquer cette dynamique différenciée (détérioration lente du talus, puis nivellement définitif). Des blocs équarris ont par ailleurs été découverts au sommet du fossé dans le seul sondage 7 , suggérant d'éventuels réaménagements postérieurs.

En l'état de la fouille, l'interprétation de cet aménagement d'envergure demeure plus qu'incertaine. Plusieurs éléments permettent toutefois, et avec beaucoup de prudence, de l'associer "sous une forme plus ou moins défensive " au prieuré de Randan: son très grand gabarit, son implantation au nord-est de celui-ci et la présence dans son comblement de mobilier domestique (suggérant une phase d'abandon et une réappropriation de l'espace situées entre le $\mathrm{XII}^{\mathrm{e}}$ et le $\mathrm{XIII}^{\mathrm{e}} \mathrm{s}$.). Cette période durant laquelle le paysage est peu à peu modifié intervient avant le démantèlement, au XIv ${ }^{\mathrm{e}} \mathrm{s}$, du mur d'enceinte du prieuré. 
INDEX

Index géographique : Rhône-Alpes, Loire (42), Feurs

operation Opération préventive de diagnostic (OPD)

Mots-clés : nécropole, église, prieuré

Index chronologique : Moyen Âge

Keywords : Medieval Period

AUTEURS

ÉRIC THÉVENIN

Inrap 